\title{
S-6436 の治療効果
}

\author{
東京共済病院内科 \\ 中川圭一 小山 優 橋本 嘉
}

Key words: $\quad$ S-6436 (long-acting preparation of Cephalexin), Clinical evaluation

S-6436は塩野義製薬研究所で開発された新しい Cephalexin 製剤である。本剤は，1 カプセル中 に胃溶顆粒と腸溶顆粒を $3: 7$ に配合した long action の CEX 製剤である。

上田 ${ }^{1)}$ ，真下 ${ }^{2)} ら に よ れ は ゙ ， S-6436 ， 500 \mathrm{mg} \mathrm{を}$ 食後に投与した際の 血中濃度は $5 \sim 6$ 時間後が peak で $4.9 \mu \mathrm{g} / \mathrm{ml}$ を示し，10時間後に特いても detectable であり，1回 500〜 1,000mg，1日 2 回の投与で臨床効果が期待できることが報告され ている.

われわれは本剤を呼吸器感染症および尿路感染 症の25例に使用し，すぐれた治療効果を壳たの で，ここに報告する。

\section{臨床成績}

\section{1. 対象症例执よび投与方法}

対象患者は，外来通院または入院中の患者であ $\eta$, 呼吸器感染症 18 例, 尿路感染症 7 例の計 25 例 である。

呼吸器感染症は, 扁桃炎 4 例, 咽頭炎 5 例, 気 管支炎 4 例，肺炎 5 例であり，これらのうち扁桃 炎の 1 例に慢性腎炎, 咽頭炎の 1 例に気管支喘 息，その他 2 例に気管支拡張症と 1 例に気管支喘 息の基礎疾患を有している.

尿路感染症は，腎孟腎炎 3 例，膀脂炎 4 例であ り，腎結石に腎孟腎炎を合併した 2 例以外は，単 純な尿路感染症である。

年齢は18歳から75歳の, 男性 8 例, 女性17例で あつた。

投与量は全例 1 日 $1 \mathrm{~g}$, 朝夕 2 回食直後飞分服 投与，投与期間は 3 日間から14日間であり，総投 与量は $3 \mathrm{~g} \sim 14 \mathrm{~g}$ であつた。
効果判定は, 呼吸器感染症については, 発熱, 咳嗽, 喀痰, 胸部理学的所見等の自他覚的臨床症 状, 胸部レ線所見和よび白血球数, 血沈, CRP 等の検查所見を総合的に判断し, 著効, 有効, や や有効抢よび無効と判定した，尿路感染症は尿中 細菌，尿沈椬所見ならびに自覚症状を指標とし て，以上の 3 項目のすべてに改善が認められたも のを著効，いずれか 1 つ上上項目が改善したも のを有効，すべて無変化あるいは悪化したものを 無効と判定した。

2. 臨床治験成績

1）呼吸器感染症の概要は Table 1 に示した。

a) 扁桃炎 ( 4 例)

症例 $2 ， 3$ で著効がみられた。症例 $1 ， 4$ は有 効であつた。な特症例 4 は，4 年前に扁桃炎から 腎炎を併発した患者で, その後も時々扁桃炎をく り返していたが，今回は来院の 2 日前より，咽頭 痛, 発熱, 血尿を訴光ていた。本剂使用 5 日目に は自覚症状ほぼ軽快，検査所見も改善，さらに 2 日間の投薬で全快した。

b) 咽頭炎（5 例）

症例 $6,7,9$ は有効, 症例 5,8 は症状の改 善に 5 日間以上を要したのでやや有効とした.

c) 気管支炎 (4 例)

症例11は急性気管支炎で有効, 症例 12 と13は慢 性の肺疾患に気管支炎を合併したもので発熱，咳 嗽, 喀痰, 白血球増多がくり返し出現している症 例であるが有効であつた，症例10は，約 1 力月前 から咳嗽，喀疢が続き，次第に増強するために来 院，本剂の投与により検査所見の改善は充分であ つたが臨床症状が残つたので，やや有効とした。 


\begin{tabular}{|c|c|c|c|c|c|c|c|c|c|c|c|c|c|c|c|c|c|c|c|}
\hline & 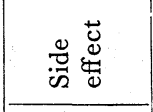 & 1 & 1 & 1 & 1 & 1 & 1 & 1 & I & 1 & 1 & 1 & 1 & 1 & 它 & 1 & $\overleftarrow{\leftarrow}$ & 1 & 1 \\
\hline & 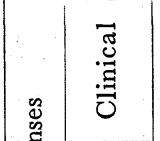 & $\begin{array}{l}\text { ¿̊口 } \\
80\end{array}$ & 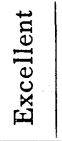 & 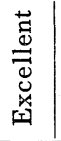 & 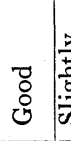 & 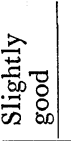 & $\begin{array}{l}-8 \\
0 \\
0\end{array}$ & $\begin{array}{l}\square \\
8 \\
0 \\
0\end{array}$ & 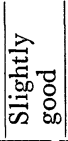 & . & 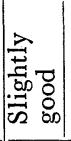 & $\begin{array}{l}\overrightarrow{0} \\
\dot{0} \\
\dot{0}\end{array}$ & $\begin{array}{l}8 \\
8 \\
0\end{array}$ & 8 & 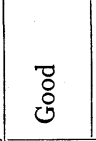 & 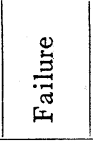 & $\begin{array}{l}\overline{8} \\
8 \\
ن\end{array}$ & ': & 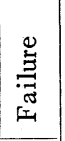 \\
\hline & 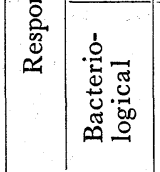 & $\begin{array}{l}5 \\
0 \\
0 \\
\text { है }\end{array}$ & 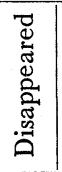 & 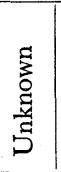 & $\begin{array}{l}\text { है } \\
\text { है } \\
\text { है } \\
5\end{array}$ & $\begin{array}{l}5 \\
0 \\
0.5 \\
5 \\
5\end{array}$ & $\backslash$ & $\begin{array}{l}5 \\
0 \\
0 \\
\text { है } \\
\text { है }\end{array}$ & 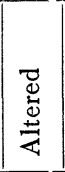 & 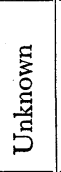 & 㺼 & 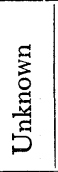 & 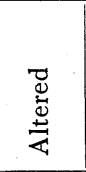 & 总 & 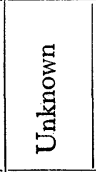 & 总 & 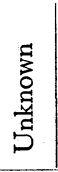 & $\begin{array}{l}5 \\
0 \\
5 \\
5 \\
5\end{array}$ & 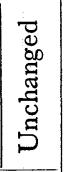 \\
\hline & 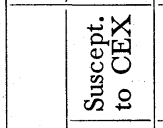 & $\begin{array}{l}\text { है } \\
5 \\
5 \\
5\end{array}$ & 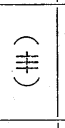 & $\lambda$ & $\mid \begin{array}{c}0 \\
0 \\
0 \\
\text { zै } \\
5 \\
\end{array}$ & \begin{tabular}{l|} 
\\
5 \\
0 \\
: \\
5 \\
\end{tabular} & $\backslash$ & 丰 & 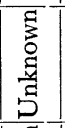 & $\backslash$ & $\backslash$ & $\backslash$ & 广 & 彗表 & $\begin{array}{l}\text { है } \\
\text { ह } \\
\text { है } \\
5\end{array}$ & 兲き & $\backslash$ & $\begin{array}{l}5 \\
5 \\
5 \\
5\end{array}$ & I \\
\hline & 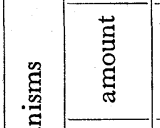 & $\begin{array}{l}\dot{0} \mathrm{i} \\
\text { ले }\end{array}$ & 害 & $\backslash$ & \pm & $\begin{array}{l}5 \\
0 \\
0 \\
5 \\
5\end{array}$ & $\backslash$ & ‡きき & $\mid \begin{array}{c}5 \\
0 \\
\vdots \\
\text { है } \\
5\end{array}$ & $\backslash$ & $\backslash$ & $\backslash$ & 丹苹主 & †さ & 琶角 & 全さ & 1 & 王至 & 拝 \\
\hline & 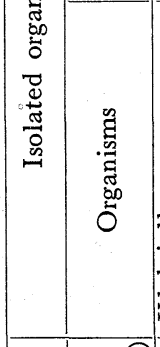 & 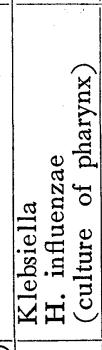 & 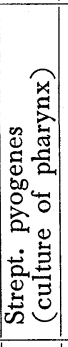 & $\backslash$ & 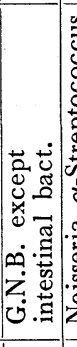 & 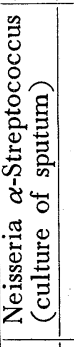 & $\backslash$ & 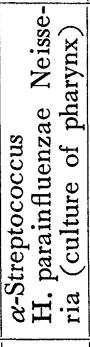 & 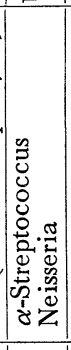 & $\searrow$ & $\backslash$ & & 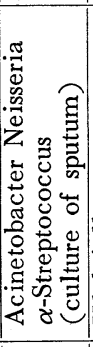 & 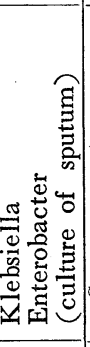 & 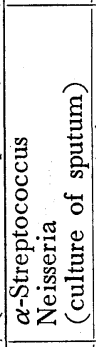 & 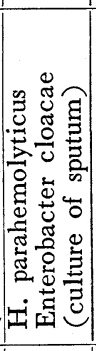 & & 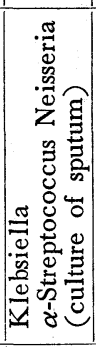 & 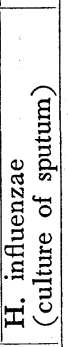 \\
\hline & 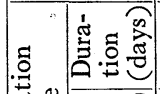 & $\infty$ & $\sim$ & 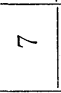 & 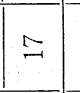 & $\sim$ & $\sim$ & $\sim$ & $\Rightarrow$ & $N$ & $\sim$ & $\sim$ & $\cong$ & 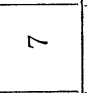 & $\sim$ & $\infty$ & $\exists$ & 으 & 10 \\
\hline & 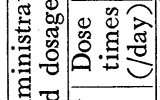 & $\sim$ & $N$ & $\sim$ & $\sim$ & $\sim$ & $\sim$ & $\sim$ & $\sim$ & $\sim$ & $\sim$ & $\sim$ & $\sim$ & $\sim$ & $N$ & $\sim$ & $\infty$ & $\sim$ & $N$ \\
\hline & 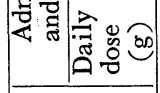 & $\stackrel{9}{-}$ & $|\stackrel{\circ}{-}|$ & $\stackrel{\circ}{-}$ & $\stackrel{\circ}{-}$ & $\stackrel{0}{-}$ & $\stackrel{\circ}{-}$ & $\stackrel{\circ}{-}$ & \begin{tabular}{|c|}
$\stackrel{0}{-}$ \\
-1
\end{tabular} & $\stackrel{\circ}{-}$ & $\stackrel{\circ}{-}$ & $\stackrel{0}{-}$ & $\stackrel{\circ}{-}$ & $\stackrel{\circ}{-}$ & $\stackrel{\circ}{-}$ & $\stackrel{\circ}{-}$ & $\stackrel{0}{-}$ & $\stackrel{\circ}{-}$ & $\stackrel{0}{0}$ \\
\hline & 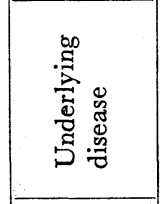 & 1 & 1 & 1 & $\mid$ & |⿹丁口 & 1 & 1 & 1 & 1 & 1 & 1 & 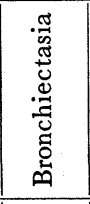 & 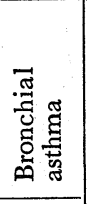 & 1 & 1 & 1 & 1 & 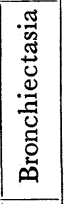 \\
\hline & 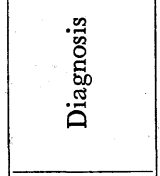 & 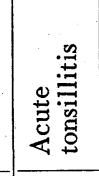 & $=$ & $=$ & 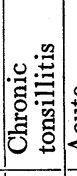 & 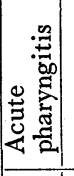 & $=$ & $=$ & $=$ & $=$ & $\mid$\begin{tabular}{r|} 
\\
$\mid$ \\
0
\end{tabular} & $=$ & 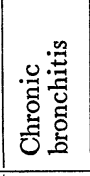 & $=$ & 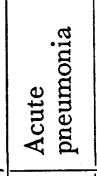 & $=$ & $=$ & $=$ & 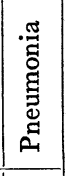 \\
\hline & $\stackrel{x}{\infty}$ & 垊 & $\Sigma$ & $\Sigma$ & $\Sigma$ & $\Sigma$ & 工 & 工 & $\Sigma$ & 5 & $\Sigma$ & 工 & 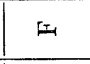 & ⿷匚 & $\Sigma$ & 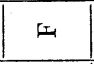 & 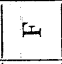 & I & 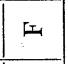 \\
\hline & $\begin{array}{l}0 \\
\stackrel{0}{\infty} \\
\end{array}$ & $\stackrel{\infty}{\sim}$ & $\ddot{m}$ & $\hat{N}$ & $\stackrel{\infty}{-}$ & $\stackrel{\infty}{\stackrel{\infty}{\prime}}$ & $\stackrel{\infty}{\forall}$ & $\infty$ & $F$ & $m$ & ले & 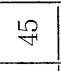 & 10 & $\tilde{\delta}$ & $\stackrel{\infty}{\rightarrow}$ & $\stackrel{\llcorner}{\sim}$ & $\vec{\sim}$ & m & $\vec{m}$ \\
\hline & 売 & $\dot{s}$ & $\begin{array}{l}\dot{4} \\
\dot{4}\end{array}$ & $\begin{array}{l}0 \\
0\end{array}$ & $\dot{i}$ & $\begin{array}{l}\dot{2} \\
\dot{2}\end{array}$ & $\begin{array}{l}\dot{z} \\
\dot{\Sigma}\end{array}$ & 芒 & $\begin{array}{l}\ddot{y} \\
\dot{\lambda}\end{array}$ & $\begin{array}{l}\dot{z} \\
\dot{\Sigma}\end{array}$ & $\underset{\Sigma}{\dot{\Sigma}}$ & $\begin{array}{l}\dot{2} \\
\dot{\Sigma}\end{array}$ & $\dot{p}$ & $\begin{array}{l}\dot{\Sigma} \\
\dot{z}\end{array}$ & $\begin{array}{l}\dot{1} \\
\dot{1}\end{array}$ & $\underset{\Sigma}{i}$ & $\ddot{x}$ & $\dot{z}$ & $\begin{array}{l}\dot{x} \\
\dot{4}\end{array}$ \\
\hline & $\dot{z}$ & $r$ & $|v|$ & $\infty$ & 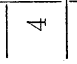 & 10 & 0 & $\Lambda$ & $\infty$ & 0 & 으 & $\Rightarrow$ & $\cong$ & $\ddot{m}$ & $\exists$ & $\stackrel{10}{-1}$ & $\mid \stackrel{0}{0}$ & $\Xi$ & $\mid \stackrel{\infty}{\rightarrow}$ \\
\hline
\end{tabular}




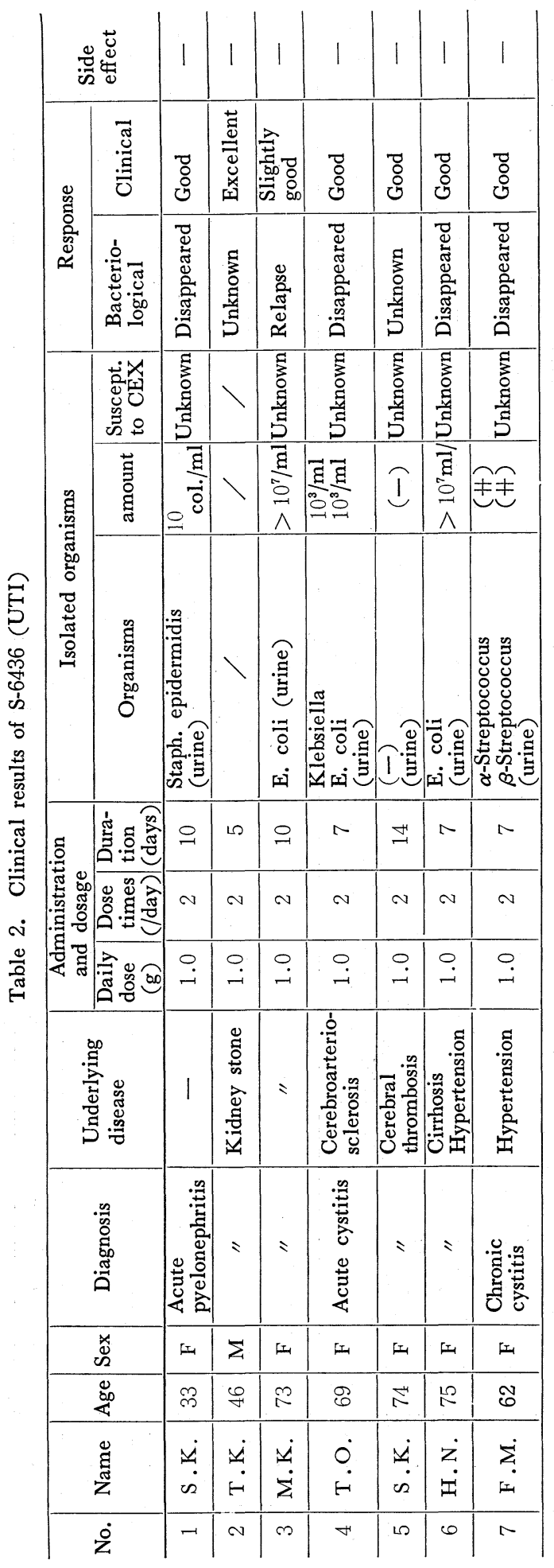

d) 肺炎 ( 5 例)

症例 $14,16,17$ が有効であり, 症例14は本剤 投与前に $\mathrm{AB}-\mathrm{PC}(1 \mathrm{~g} 1$ 日) を3 日間, さらに CER( $1 \mathrm{~g} 1$ 日)を 3 日間投薬され治療を受けたが 解熱せず，右上中肺野に陰影を認められ肺炎と診 断されて来院した症例であるが，本剤の投薬 3 日 後には解熱して臨床症状も軽快，7日後には胸部 レ線所見, 検査所見とも改善した. この症例は本 剂使用前の AB-PC, CER の副作用で S-GOT, SGPT に軽度の上昇があり，本剂の投薬によつて 更に S-GOT, S-GPT の上昇をみたため, 本剤の 副作用とした。な投投薬終了後 1 週目の検查で は, 正常に戻つていた. 症例16は左下肺野に陰影 を認めた例で, 本剤投薬 3 日目, 臨床症状悪化し たので他剤に変更した。

2）尿路感染症の概要は Table 2 に示した。

a) 腎盘腎炎 ( 3 例)

症例 2，3 は腎結石を合併した急性腎盂腎炎で あり, 前者は著効であつたが, 後者の尿中細菌は E. coli であり, 臨床症状は軽快したが投与期間 中に尿所見が悪化したためやや有効とした。

b) 膀胱炎 ( 4 例)

3 例は急性膀胱炎, 他の 1 例は慢性の膀胱炎で ある. 尿中から検出した細菌は，Klebsiella，E。 coli，Streptococcus であつたが，すべて有効であ つた.

\section{3. 副作用}

検査所見で, S-GOT, S-GPT の上昇したものが 1 例，S-GPT の軽度上昇したものが 1 例と計 2 例にみられたが，いずれも投与中止後正常に復し ている。また，Alkali-P が投与前から高值を示し たものが 1 例あつたが，投与後もほぼ同程度であ つた。 その他自覚症状を含めて本剂による副作用 と思われるものはなかつた。

投与前後の検查所見は Table 3 に示すごとくで ある。

$$
\text { むすび }
$$

われわれは, long action の新しい Cephalexin の製剂である S-6436を 500mg 宛 1 日 2 回投与に 
Table 3 Labratory findings

\begin{tabular}{|c|c|c|c|c|c|c|c|c|c|c|c|c|c|c|c|c|}
\hline \multirow{2}{*}{ No. } & \multicolumn{2}{|c|}{$\operatorname{RBC}\left(\times 10^{4}\right)$} & \multicolumn{2}{|c|}{ WBC } & \multicolumn{2}{|c|}{$\mathrm{Hb}$} & \multicolumn{2}{|c|}{ S-GOT } & \multicolumn{2}{|c|}{ S-GPT } & \multicolumn{2}{|c|}{ Al-P } & \multicolumn{2}{|c|}{ BUN } & \multicolumn{2}{|c|}{ Creatinine } \\
\hline & Pre. & Post. & Pre. & Post. & Pre. & Post. & Pre. & Post. & Pre. & Post. & Pre. & Post. & Pre. & Post. & Pre. & Post. \\
\hline \multicolumn{3}{|c|}{ Cases of RTI } & & & & & & & & & & & & & & \\
\hline 1 & 413 & 330 & 12,000 & 5,000 & 12.1 & 9.0 & 16 & 14 & 18 & 11 & 5.9 & & 21.3 & 12.6 & 1.0 & 0.8 \\
\hline 2 & 465 & & 14,800 & 7,000 & 15.3 & & 14 & & 9 & & & & 16.3 & & 1.2 & \\
\hline \multicolumn{17}{|l|}{3} \\
\hline 4 & 521 & 458 & 9,100 & 4,700 & 17.5 & 15.2 & 24 & 11 & 14 & 11 & 7.6 & 5.8 & 14 & 13.2 & 1.4 & 1.1 \\
\hline \multicolumn{17}{|l|}{5} \\
\hline 6 & & 375 & & 5,300 & & 12.0 & & & & & & & & & & \\
\hline 7 & 395 & & 6,100 & & 12.7 & & & & & & & & & & & \\
\hline 8 & 482 & & 7,400 & 9,200 & 16.1 & & & 13 & & 11 & & & & & & \\
\hline 9 & 400 & 401 & 5,900 & 7,000 & 12.8 & 13.1 & 13 & 11 & 7 & 9 & & & 13.0 & 13.2 & 0.5 & 0.7 \\
\hline 10 & 465 & 470 & 7,300 & 6,000 & 15.4 & 15.5 & & & & & & & & & & \\
\hline 11 & 412 & 398 & 11,000 & 6,800 & 12.6 & 11.4 & & & & & & & & & & \\
\hline 12 & 296 & 341 & 6,400 & 5,700 & 10.4 & 12.0 & & 11 & & 7 & & & & & & \\
\hline 13 & 439 & 425 & 9,900 & 5,700 & 13.3 & 13.3 & 14 & & 12 & & 9.0 & & 10 & & 0.9 & \\
\hline 14 & 451 & 431 & 13,600 & 7,400 & 14.1 & 13.8 & 36 & 52 & 25 & 56 & 33.0 & 34.0 & 13.8 & & 1.1 & \\
\hline 15 & & & 6,400 & 6,300 & & & & & & 25 & & 14 & & 17.8 & & \\
\hline 16 & 450 & 385 & 8,000 & 7,100 & 14.6 & 12.4 & 22 & 27 & 24 & 43 & 5.8 & 3.7 & 12.8 & 14.7 & 0.9 & 0.7 \\
\hline 17 & 416 & 387 & 4,800 & 7,900 & 12.4 & 11.8 & & 11 & & 8 & & 4.1 & & 12.0 & & 0.6 \\
\hline 18 & 462 & 415 & 14,800 & 15,800 & 9.8 & 9.0 & 20 & 16 & 22 & 11 & 11.6 & 10.0 & 20.6 & 14.9 & 1.0 & 0.7 \\
\hline \multicolumn{3}{|c|}{ Cases of UTI } & & & & & & & & & & & & & & \\
\hline 1 & 362 & 336 & 4,200 & 4,400 & 11.4 & 10.7 & 36 & & 20 & & 5.8 & & 12.0 & & 0.7 & \\
\hline 2 & 436 & 440 & 13,000 & 6,700 & 14.6 & 13.7 & 18 & & 14 & & 5.3 & & 14.4 & & 1.4 & \\
\hline 3 & 346 & 321 & 9,100 & 5,900 & 12.1 & 11.1 & & 7 & & 6 & & 7.3 & & 16.0 & & 0.9 \\
\hline \multicolumn{17}{|l|}{4} \\
\hline 5 & 493 & 498 & 9,200 & 9,100 & 15.9 & 16.1 & & 16 & & 7 & & 4.8 & & 16.2 & & 1.0 \\
\hline 6 & 359 & 377 & 3,700 & 3,600 & 9.8 & 10.1 & 31 & 31 & 14 & 16 & 20.6 & 23.6 & 18.3 & 16.2 & 0.9 & 1.0 \\
\hline 7 & & 373 & & 3,600 & & 12.1 & & 16 & & 13 & & 4.2 & & 18.9 & & 0.7 \\
\hline
\end{tabular}

より，18例の呼吸器感染症抢よび 7 例の尿路感染 症を治療し, 呼吸器感染症では著効, 有効13例で $72.2 \%$ ，尿路感染症では著効，有効 6 例で $85.7 \%$ の有効率を光た。

副作用として本剂投与後 S-GOT, S-GPT の上 昇したものが 2 例にみとめられたが，投与終了後 まもなく正常值復している。 その他臨床的にも 特記すべき副作用はなかつた。

本剤は 500mg を1 日2回の投与で, CEX 250 $\mathrm{mg} 1$ 日 4 回投与と同程度の有効率を光たことか ら，軽症ないし中等症の感染症飞対し有用性のあ
る薬剤と考光られる。外来患者あるいは軽作業を しながら治療をらけるものにとつては，1日2回 服用で効果があるといらことは大きな利点である と思われる。

\section{文献}

1）上田 泰, 松本文夫, 斉藤 篤, 大森雅久, 小 林千鶴子, 柴 孝也, 山路武久, 并原裕宣: 持 続性. Cephalexin (S-6435,S-6436)にかんする研 究。最新医学, 32 (6) 1189-1194, 1977.

2) 真下啓明, 深谷一太 : Cefalexin 持続性製剂 (S-6435,S-6436) について. 最新医学, 32(6) 1195-1202, 1977. 
Clinical Studies on S-6436

\section{Keiichi NAKAGAWA, Masaru KOYAMA and Yoshimi HASHIMOTO \\ Department of Internal Medicine, Tokyo Kyosai Hospital}

S-6436 is a new long-acting preparation of Cephalexin. This report describes the clinical trial with this drug.

S-6436 was administered at the dose $500 \mathrm{mg}$ b.i.d. after meal. Clinical results of S-6436 in 18 cases of respiratory tract infections were excellent in 2 cases, good in 11 cases, slightly good in 3 cases and failure in 2 cases. In 7 cases in urinary tract infections, clinical results obtained were excellent in 1 case, good in 5 cases and slightly good in 1 case. Transient and slight increase of S-GOT and S-GPT was noted in 1 case, and S-GPT in 1 case.

It is considered that S-6436 and Cephalexin are equal in points of effectiveness and safety in the treatment of mild or moderately severe infections. Therefore, S- 6436 of $500 \mathrm{mg}$ b.i.d. after meal may be more advantageous for the patients than Cephalexin 250 mg q.i.d. . 